\title{
A Novel Intensive Distribution Logistics Network Design and Profit Allocation Problem considering Sharing Economy
}

\author{
Mi Gan $\left(\mathbb{D},{ }^{1,2,3,4}\right.$ Shuai Yang, ${ }^{1}$ Dandan Li, ${ }^{1}$ Mingfei Wang, ${ }^{1}$ Si Chen, ${ }^{1}$ \\ Ronghui Xie, ${ }^{1}$ and Jiyang Liu ${ }^{1}$ \\ ${ }^{1}$ School of Transportation and Logistics, Southwest Jiaotong University, Chengdu, Sichuan 610031, China \\ ${ }^{2}$ Sino-US Global Logistics Institute, Shanghai Jiaotong University, Shanghai, China \\ ${ }^{3}$ National United Engineering Laboratory of Integrated and Intelligent Transportation, Southwest Jiaotong University, \\ Chengdu, Sichuan 610031, China \\ ${ }^{4}$ National Engineering Laboratory of Big Data Application in Integrated Transportation, Southwest Jiaotong University, \\ Chengdu, Sichuan, China \\ Correspondence should be addressed to Mi Gan; yyganmi@gmail.com
}

Received 5 September 2017; Accepted 4 March 2018; Published 11 April 2018

Academic Editor: Carlos Gershenson

Copyright (C) $2018 \mathrm{Mi}$ Gan et al. This is an open access article distributed under the Creative Commons Attribution License, which permits unrestricted use, distribution, and reproduction in any medium, provided the original work is properly cited.

\begin{abstract}
The rapid growth of logistics distribution highlights the problems including the imperfect infrastructure of logistics distribution network, the serious shortage of distribution capacity of each individual enterprise, and the high cost of distribution in China. While the development of sharing economy makes it possible to achieve the integration of whole social logistic resources, big data technology can grasp customer's logistics demand accurately on the basis of analyzing the customer's logistics distribution preference, which contributes to the integration and optimization of the whole logistics resources. This paper proposes a kind of intensive distribution logistics network considering sharing economy, which assumes that all the social logistics suppliers build a strategic alliance, and individual idle logistics resources are also used to deal with distribution needs. Analyzing customer shopping behavior by the big data technology to determine customer's logistics preference on the basis of dividing the customer's logistics preference into high speed, low cost, and low pollution and then constructing the corresponding objective function model according to different logistics preferences, we obtain the intensive distribution logistics network model and solve it with heuristic algorithm. Furthermore, this paper analyzes the mechanism of interest distribution of the participants in the distribution network and puts forward an improved interval Shapley value method considering both satisfaction and contribution, with case verifying the feasibility and effectiveness of the model. The results showed that, compared with the traditional Shapley method, distribution coefficient calculated by the improved model could be fairer, improve stakeholder satisfaction, and promote the sustainable development of the alliance as well.
\end{abstract}

\section{Introduction}

With the rapid development of e-commerce and online retail industry, China's logistics volume increased rapidly. According to statistics, China's express quantity reached 315.5 billion in 2016, nearly half of global express quantity and the express industry has grown by more than $50 \%$ over six consecutive years. Compared with the increasing demand of logistics, logistics distribution network and infrastructure lag behind obviously, which restricts the development of logistics, retail, and e-commerce. In order to solve the problem of insufficient logistics resources, there are two main ideas. On the one hand, establishing more logistics facilities and, on the other hand, integrating and optimizing the existing social logistics resources. This paper focuses on the second point.

Sharing economy is a rapidly developed business model since 2010; it takes a variety of forms, including using information technology to provide individuals with information that enables the optimization of resources through the mutualization of excess capacity in goods and services [1]. In recent years, the sharing economy has been wildly used in many fields such as agriculture, finance, property, 


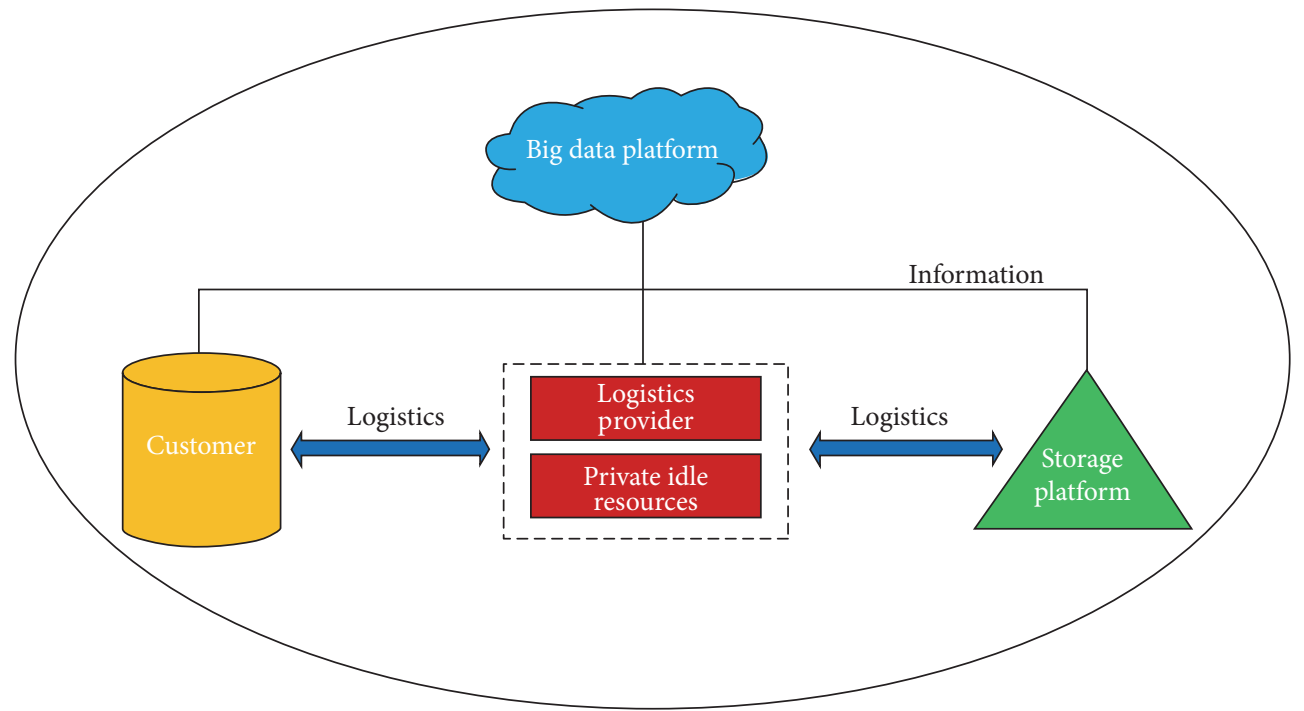

FIGURE 1: Intensive distribution logistics network structure considering sharing economy.

transportation, and technology; there are also many attempts to apply the sharing economy into logistics field. Some companies applied the sharing economy model to local delivery: Uber launched an app called Uber Eats which enables users to register to be drivers and can get paid for delivering food [2]; Instacart applied sharing economy model to grocery delivery by taking contract with workers who can use their personal vehicles to deliver goods to customers [3, 4]. Sharing economy has also been wildly used in express industry; the largest express alliance Cainiao in China aims to achieve rational utilization of the whole society logistics resources by integrating resources of seller, warehouse, and distribution based on big data analysis and implementation rules. With the development of sharing economy, it is possible to integrate the whole society's logistics resources. Meanwhile, the development of big data technology can provide technical support for strategic alliances. The express enterprises could make full use of big data technology on the basis of constructing strategic alliance and actively mobilize private idle logistics resources of the society, which is predicted to be crucial to establish the competitive advantage of the enterprise.

Logistics volume carried by distribution network of the whole society is known as the units and residents items, which is an important part of the total social logistics, including the baggage, parcels and letters in postal services, community donations, goods belonging to groups or residents which need to be transported, and logistics service items due to moving house in railway and air transportation [5]. As the source of more than $60 \%$ of the residents' logistics demand is produced by the transaction of electronic commerce, big data by user transactions in e-commerce network could be conducive to further analysis and determination of logistics preference of customers [6]. Customers log in electricity supplier website, browse products, add to cart, give up the goods or not, select the logistics distribution enterprises, and so on, which would produce a huge user preference shopping behavior data, credit, and payment data. A certain mechanism to analyze and classify user preferences could be utilized, and the preferences could be met through targeted services.

In terms of terminal distribution, the logistics distribution terminals mainly cover the modes shown in Table 1 at home and abroad.

With the emergence of the sharing economy model, more and more governments, enterprises, and scholars begin to consider how to make use of the private idle logistics capability to serve the social logistics and save the social cost. Intensive distribution logistics network structure considering sharing economy could be represented as Figure 1. The design problem is analyzing and determining the user logistics preferences through the electricity supplier user data, which assumes that strategic alliances would take full account of idle private logistics capability to canvass, provide terminal delivery service in logistics first mile and last mile, and meet the needs of users after segmentation.

The logistics resources considered in this paper mainly include logistics resources of third-party logistics companies, private idle resources of social logistics, and warehousing resources. At the same time, it takes into consideration the capacity and characteristics of freight transportation by various modes such as railway, highway, aviation, and shipping, to optimize the integration and logistics capabilities.

The constructions of strategic alliances and private logistics idle resources meet the demand of distribution together, which could not only greatly reduce the total cost of social distribution, but also improve customer satisfaction. Due to a certain degree of difference including resource input, risk taking, joining time, and effort of alliance between members of the alliance, they should obtain different profits, and the 


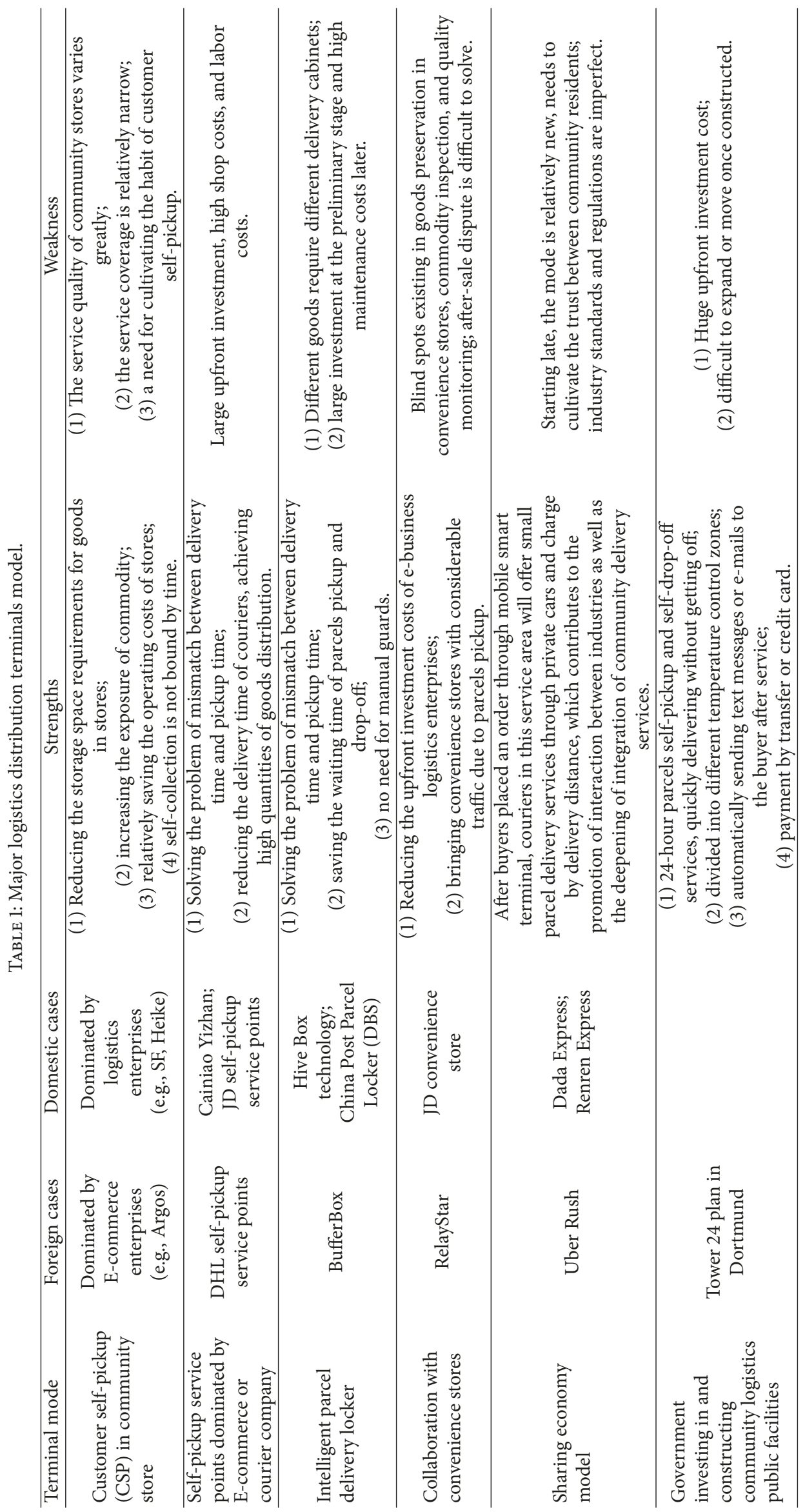


scientific method of profit allocation is the key to ensure the stable operation of the strategic alliance.

The research of this paper is mainly divided into two aspects. For one thing, assuming that the social idle logistics resources can be fully employed under the strategic alliance of whole society logistic enterprises, then in order to meet the different demands of consumers, a kind of intensive distribution logistics network considering sharing economy is proposed and solved by heuristic algorithm. For another, in order to avoid the profit allocation conflict and the further threat to the stability of the alliance, an improved interval Shapley value method taking both the satisfaction and the contribution of alliance members into account is proposed to promote the sustainable development.

\section{Literature Review}

The design of distribution logistics network could be divided into multistage distribution and single stage distribution. The multistage distribution problem is usually solved as a single stage transportation problem [7], and the single stage delivery problem could also be regarded as the vehicle routing problem [8]. In addition, the facility location problem is also closely related to the design of the distribution logistics network [9]. Jansen et al. took the multiple traffic mode selection problem into the distribution problem [10]; Beamon summarized the existing supply chain distribution problems and divided them into two types: the quality model and the quantity model [11]; Gülpınar et al. studied facility location and network design issues at the same time, aiming to minimize the maximum transport time from customers to facilities [12]. Zarandi et al. investigated positioning transport route problem with time window under uncertainty (LRPTW). The authors assumed that customer demand and travel time are fuzzy variables and established a fuzzy chance constrained programming (CCP) model using the credit theory, and the simulated annealing algorithm was applied to solve the problem [13]. Recent researches focus on considering the distribution network design problem under different situations, for example, model construction considering the traffic congestion [14], emergency condition [15], and environment constraints $[16,17]$. The solution algorithm is usually based on intelligent algorithm or heuristic algorithm, and the performance and efficiency of the algorithm are relatively mature.

In terms of profit allocation of strategic alliances, scholars have adopted quantitative analysis methods such as alliance Shapley value [18], core [19], Weber set [20], nucleolus solution [21], negotiation pricing method [22], and game method [23]. As an important solution of the classical cooperative game theory, the Shapley method has been widely applied to solve the cooperative income distribution problem in the classical cooperative game. However, the application of the classical Shapley value method for profit allocation has some defects. For example, when the real problem cannot meet the assumptions of classical cooperative game, the classical Shapley value method is no longer applicable; and the Shapley value method takes the marginal contribution of the alliance members as the sole basis of profit allocation, ignoring characteristic differences among members in the alliance, which has been questioned by scholars [24].

The first attempt to solve the symmetry problem was made by Shapley LS himself, who weakened the assumptions about the symmetry in Shapley value model, gave the members of the alliance the right weight, and constructed a more extensive weighted Shapley value model, and the original Shapley model is only a special case [25]. Subsequently, Owen proposed the "diagonal formula" calculation for weighted Shapley value [26, 27]. Kalai and Samet further extended the "weight" in weighted Shapley value model to the "weighting system," that is, adding an ordered coalition group based on the weight vector, which made the zero weight possible and gave an axiomatic description of weighted Shapley value in weight system [28]. At present, scholars mainly use the improved Shapley value method to carry out the profit allocation in the supply chain [29-31] and the dynamic alliance $[32,33]$ scene. At the same time, to better solve the problem of income allocation in practical cooperative game, scholars at home and abroad have studied the problem of cooperative game under uncertain environment. Aubin first put forward the concept of fuzzy cooperative game and defined a fuzzy number in the range $[0,1]$ to represent the degree of membership in a coalition, but the income of such fuzzy alliance is crisp real number [34]. Sakawa and Nishizaki proposed a cooperative strategy with clear alliance and fuzzy payoff functions [35]. Mares studied the fuzzy Shapley value of cooperative game and defined the fuzzy membership function of Shapley value, but failed to give the specific income distribution scheme of the alliance [36]. The Shapley value with fuzzy interval numbers takes the uncertainties existing in the actual allocation process into account, which could effectively solve the deficiency of classical Shapley values for accurate solutions.

Generally, there are many researches on the distribution network design, but most emphasize the cost minimization model by using the algorithm, which has its limitations. With the wave of sharing economic, this paper uses big data technology innovatively to segment customer logistics preferences and construct intensive distribution logistics network considering sharing economy through different logistics preferences to guide the design and improvement of logistics network and product. In terms of profit allocation, existing studies focused on the correction coefficient of distribution of Shapley, but the correction coefficient determined currently has three main problems: (1) the considered factors affecting the cooperation profit distribution are single; (2) the most comprehensive correction coefficients are determined by AHP and fuzzy evaluation method which show obvious subjective tendency; (3) the importance of alliance members for profit satisfaction is ignored. In view of this, combined with the basic characteristics and operation mechanism of express enterprise alliance, this paper proposes an improved interval Shapley value method considering both satisfaction and contribution to modify the distribution coefficient value method, which obtains a fairer and more reasonable profit allocation result. 


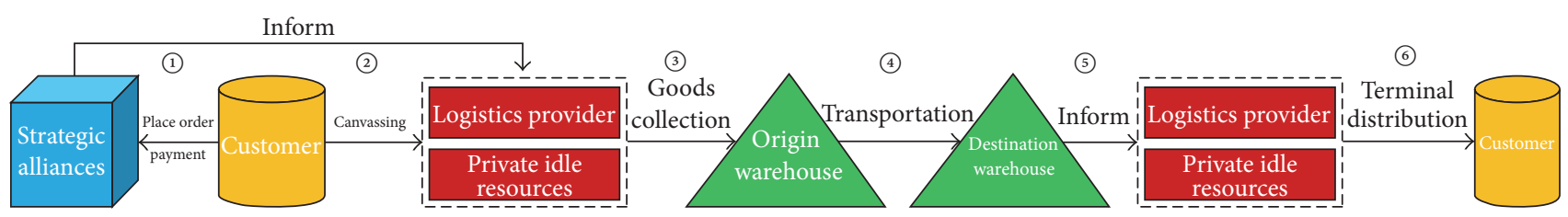

FIGURE 2: Conceptual model considering sharing economy.

\section{Intensive Distribution Logistics Network Design Model considering Sharing Economy}

3.1. Basic Instructions, Marking, and Assumptions. Through the analysis of the distribution network, the logistics network is divided into six parts: receiving order, canvassing, collecting goods to warehouse, transportation to destination warehouse, warehouse delivery, and terminal distribution, as shown in Figure 2.

Decisions on the design of this distribution network need to be made, including the following:

(1) When the enterprise receives orders, the alliance confirms and arranges logistics service providers or private idle resources to canvass immediately.

(2) Select original warehouse after canvass.

(3) Select transportation provider for transportation.

(4) Select appropriate destination warehouse after transportation.

(5) Choose appropriate terminal distributor.

(6) Handle terminal distribution.

At the same time, in order to facilitate the establishment of the model, according to the actual situation in reality, the following basic assumptions are made:

(1) Each customer has only one logistics preference, that is, shortest transport time, lowest cost, or lowest carbon emissions.

(2) The third-party logistics providers of the whole society and private construct strategic alliances and integrate, optimize, and configure resources.

(3) Solicitation fee of the third-party logistics distribution includes pickup and delivery to the original warehouse; terminal distribution costs of the third-party logistics providers include picking up goods from the arrival warehouse and delivering them to the final customer correspondingly.

(4) The private could use idle logistics resources to provide canvass and terminal delivery service, and the income is paid by the strategic alliance.

The description of basic parameters is as follows:

$D=\left\{d_{1}, d_{2}, \ldots, d_{d}\right\}:$ consignors;

$F=\left\{f_{1}, f_{2}, \ldots, f_{f}\right\}:$ the third-party logistics provider at the origin;
$G=\left\{g_{1}, g_{2}, \ldots, g_{g}\right\}$ : the aggregation of freight collection warehouse at the origin;

$K=\left\{k_{1}, k_{2}, \ldots, k_{k}\right\}$ : the aggregation of freight collection warehouse at the destination;

$L=\left\{l_{1}, l_{2}, \ldots, l_{l}\right\}$ : the third-party logistics provider at the destination;

$C=\left\{c_{1}, c_{2}, \ldots, c_{c}\right\}:$ aggregation of all end-customers;

$P=\left\{p_{1}, p_{2}, \ldots, p_{p}\right\}$ : aggregation of third-party logistics providers from the original warehouse to the destination warehouse;

$e=\left\{e_{1}, e_{2}, e_{3}\right\}$ : three types of customer logistics preferences based on big data analysis; $e_{1}, e_{2}, e_{3}$ represent shortest transport time, lowest logistics cost, and lowest carbon emissions individually;

$x_{d f}, y_{f g}, z_{g k}^{p}, \delta_{k l}, \varepsilon_{l c}$ are all 0-1 variables, $x_{d f}$ is equal to 1 when a third-party logistics provider in $F$ canvasses goods delivered from consignor of $D$; $y_{f g}$ equals 1 when any of the third-party logistics providers in $F$ canvasses goods and delivers them to original warehouse which belongs to $G ; z_{g k}^{p}$ takes 1 when company in $P$ undertakes transport between $g$ and $k$; $\varepsilon_{l c}$ equals 1 when selection $l_{i}$ in $L$ delivers goods to terminal end-customer belonging to $C$;

$q_{d f}, q_{f g}, q_{k l}, q_{l c}:$ logistics volume of $d-f, f-g, g-k$, $l-c$, respectively;

$\theta_{g k}^{p}$ : the transport volume of the third-party logistics provider $P$ from original warehouse $G$ to destination warehouse $K$;

$Q_{g}, Q_{k}$ : handling capability limits between original warehouses $G$ and destination warehouses $K$, respectively;

$Q_{f}, Q^{P}, Q_{l}$ : logistics capabilities limit of logistics provider set $F, P, L$, respectively;

$q_{d}, q_{c}$ : consignor's delivering amount and receiver's requirements;

$t_{d f}, t_{g}, t_{g k}^{p}, t_{k}, t_{l c}$ : canvassing time, handling time in original warehouses, transport time from original warehouse to destination warehouse, handling time in destination warehouses, and terminal distribution time;

$v_{d f}, h_{g}, c_{g k}^{p}, d_{k}, r_{l c}$ : canvassing fee of unit goods, handling fee in original warehouse, transportation fees, handling fees in destination warehouse, and terminal distribution costs; 


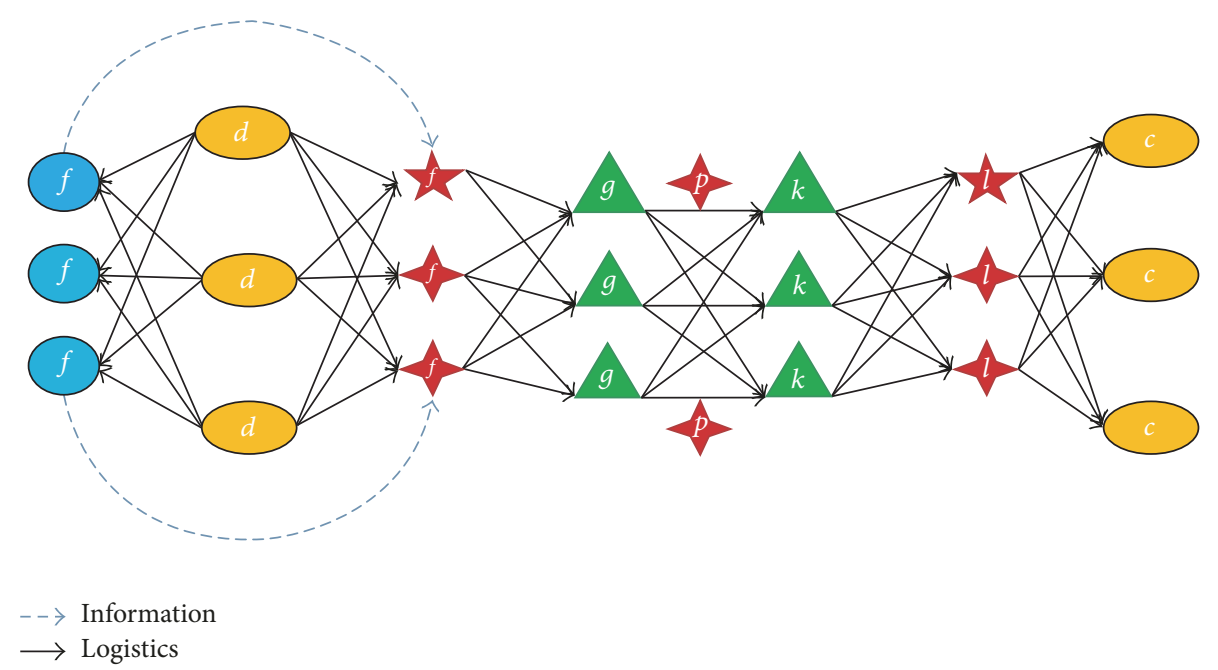

FIGURE 3: Network model considering sharing economy.

$c o_{d f}, c o_{g k}^{p}, c o_{l c}$ : carbon emissions in process of canvassing of unit goods, transportation, and terminal distribution costs due to vehicles operation;

The network model considering sharing economy could be obtained according to conceptual model and basic parameters, as shown in Figure 3.

\subsection{Multiobjective Programming Model}

\subsubsection{Customer Logistics Preference Objective Function Based on Big Data Analysis}

(1) Shortest Transport Time. Such customers mainly pursue timeliness when shopping in the electricity supplier website. The objective function could be therefore constructed to minimize the overall delivery time, as follows:

$$
\begin{aligned}
& \min \quad Z^{e 1} \\
& =\sum_{d_{1}}^{d_{d}} \sum_{f_{1}}^{f_{f}} x_{d f} t_{d f}+\sum_{f_{1}}^{f_{f}} \sum_{g_{1}}^{g_{g}} y_{f g} t_{f g}+\sum_{g_{1}}^{g_{g}} \sum_{k_{1}}^{k_{k}} \sum_{p_{1}}^{p_{p}} z_{g k}^{p} t_{g k}^{p} \\
& +\sum_{k_{1}}^{k_{k}} \sum_{l_{1}}^{l_{l}} \delta_{k l} t_{k l}+\sum_{l_{1}}^{l_{l}} \sum_{c_{1}}^{c_{c}} \varepsilon_{l c} t_{l c} .
\end{aligned}
$$

(2) Lowest Logistics Cost. The goal of this kind of customer is consistent with the goal of the general logistics network planning problem, which requires the lowest overall logistics cost, so the corresponding delivery logistics price is relatively low. The objective function can be constructed to minimize the overall distribution costs, as follows:

$$
\begin{aligned}
& \min Z^{e 2} \\
& =\sum_{d_{1}}^{d_{d}} \sum_{f_{1}}^{f_{f}} q_{d f} v_{d f}+\sum_{f_{1}}^{f_{f}} \sum_{g_{1}}^{g_{g}} q_{f g} h_{f g}+\sum_{g_{1}}^{g_{g}} \sum_{k_{1}}^{k_{k}} \sum_{p_{1}}^{p_{p}} q_{g k}^{p} c_{g k}^{p} \\
& \\
& +\sum_{k_{1}}^{k_{k}} \sum_{l_{1}}^{l_{l}} q_{k l} d_{k l}+\sum_{l_{1}}^{l_{l}} \sum_{c_{1}}^{c_{c}} q_{l c} r_{l c} .
\end{aligned}
$$

(3) Lowest Carbon Emissions. Such customers are concerned about carbon emissions during the distribution process, and they are willing to undertake environmental responsibility regardless of costs. This paper only considers the carbon emissions links including canvass, transportation, and final distribution, ignoring warehouse processing. The objective function is the minimum carbon emissions in the process of the entire distribution, which is as follows:

$$
\begin{aligned}
& \min Z^{e 3} \\
& =\sum_{d_{1}}^{d_{d}} \sum_{f_{1}}^{f_{f}} C O_{d f} q_{d f}+\sum_{g_{1}}^{g_{g}} \sum_{k_{1}}^{k_{k}} \sum_{p_{1}}^{p_{p}} C O_{g k}^{p} q_{g k}^{p} \\
& \\
& +\sum_{l_{1}}^{l_{l}} \sum_{c_{1}}^{c_{c}} C O_{l c} q_{l c} .
\end{aligned}
$$

3.2.2. Constraints on the Design of Distribution Logistics Network. According to flow conservation of logistics node, flow conservation of transport volume and arrival quantity, logistics capability limitation of third-party logistics providers, warehouse capacity limitation, overall distribution process time limitation, and the constraints of each decision variable's own attributes and relationships, the following constraints could be obtained: 


$$
\begin{aligned}
& \text { St: } \quad \sum_{d} q_{d f} x_{d f} \leq Q_{f}, \quad f \in F, d \in D, \\
& \sum_{d} q_{d f} x_{d f}=\sum_{f} q_{f g} y_{f g}, \quad d \in D, f \in F, g \in G, \\
& \sum_{f} q_{f g} y_{f g} \leq Q_{g}, \quad f \in F, g \in G, \\
& \sum_{f} q_{f g} y_{f g}=\sum_{k} \sum_{p} \theta_{g k}^{p} z_{g k}^{p}, \\
& f \in F, g \in G, k \in K, p \in P, \\
& \sum_{k} \sum_{p} \theta_{g k}^{p} z_{g k}^{p} \leq Q_{g}, \quad g \in G, k \in K, p \in P, \\
& \sum_{k} \sum_{p} \theta_{g k}^{p} z_{g k}^{p} \leq Q_{g}, \quad g \in G, k \in K, p \in P, \\
& \sum_{g} \sum_{p} \theta_{g k}^{p} z_{g k}^{p}=\sum_{l} q_{k l} \delta_{k l}, \\
& g \in G, k \in K, p \in P, l \in L, \\
& \sum_{l} q_{k l} \delta_{k l} \leq Q_{k}, \quad k \in K, l \in L, \\
& \sum_{k} q_{k l} \delta_{k l} \leq Q_{l}, \quad k \in K, l \in L, \\
& \sum_{l} q_{l c} \delta_{l c}=q_{c}, \quad c \in C, l \in L, \\
& \sum_{c} q_{c}=\sum_{d} q_{d}, \quad c \in C, d \in D \\
& x_{d f}=y_{f g}, \quad \forall f \in F, \\
& y_{f g}=z_{g k}^{p}, \quad \forall g \in G, \\
& z_{g k}^{p}=\delta_{k l}, \quad \forall k \in K, \\
& \delta_{k l}=\varepsilon_{l c}, \quad \forall l \in L, \\
& x_{d f}, y_{f g}, z_{g k}^{p}, \delta_{k l}, \varepsilon_{l c}=\{0,1\} \\
& q_{d f}, q_{f g}, q_{k l}, q_{l c}, \theta_{j k}^{p} \geq 0 \\
& d \in D, f \in F, g \in G, k \in K, p \in P, l \in L, c \in C \text {. }
\end{aligned}
$$

Constraint (4) is the logistics ability limitation of a thirdparty logistics company canvass that the consignor utilizes; Constraint (5) represents conservation of total quantity between canvassing of the third-party logistics company and its sending to original warehouse; Constraint (6) represents the handling capacity limit of original warehouse canvass capacity; Constraint (7) represents the flow conservation of original warehouse; Constraint (8) represents the handling capacity limitation of the transmission capacity of original warehouse; Constraint (9) represents the capacity quantity handling limitation of the destination warehouse; Constraint (10) represents the flow conservation of destination warehouse; Constraint (11) represents the handling capacity limitation of the transmission capacity of destination warehouse; Constraint (12) represents the terminal distribution capability limitation of the third-party logistics company; Constraint (13) represents conservation of the total amount of customer receipt and its demand; Constraint (14) represents flow conservation between sending quantity of origin and received quantity of destination; Constraints (15)-(18) represent a commitment relationship between 0-1 variables to help in decision making; Constraints (19) and (20) are 0, 1 constraints and nonnegative constraints for decision variables.

3.3. Model Transformation Mechanism and Algorithm. Through big data analysis of the user's historical behavior, we could get the proportion of the customers of all kinds of logistics preferences in the total customers and deal with the objective functions (1)-(3).

3.3.1. Normalization Processing. Since the units of different objective functions are different, it is necessary to handle the values in (1)-(3) by the normalization method. Vector normalization method is used here as follows:

$$
\begin{aligned}
& z^{-e 1}=\frac{z^{e 1}}{\sqrt{z^{e 1^{2}}+z^{e 2^{2}}+z^{e 3^{2}}}}, \\
& z^{-e 2}=\frac{z^{e 2}}{\sqrt{z^{e 1^{2}}+z^{e 2^{2}}+z^{e 3^{2}}}}, \\
& z^{-e 3}=\frac{z^{e 3}}{\sqrt{z^{e 1^{2}}+z^{e 2^{2}}+z^{e 3^{2}}}} .
\end{aligned}
$$

3.3.2. Handing by the Linear Weighted Sum Method. By observing the objective function, it can be seen that the objective functions (1), (2), (3) are the minimization of the objective function, and the total objective function value of the distribution network is obtained by the linear weighted sum method, and the total model is as follows:

$$
\begin{aligned}
\text { model DLND: } \min & Z=\alpha z^{-e 1}+\beta z^{-e 2}+\gamma z^{-e 3} \\
\text { constraints: } & (4)-(20)
\end{aligned}
$$

3.3.3. Model Solving Algorithm. It could be observed that the DLND model is a classic mixed integer programming model. Branch and bound method, cutting plane method, or heuristic algorithm and genetic algorithm, simulated annealing algorithm, and other intelligent algorithms could solve this kind of problem effectively. In addition, various optimization software tools have more mature toolboxes, such as MATLAB which has been used to solve such problems. For practical problems, the above method could be used to solve the problem effectively. 


\section{Analysis of Members' Profit Allocation in Intensive Distribution Logistics Network}

This section analyzes benefits allocation in the distribution network and proposes an improved Shapley value method which considers both contribution and satisfaction.

4.1. Interval Shapley Value Method. The interval Shapley function is consistent with the classical Shapley function in the form, but the former is the natural expansion of the latter under the fuzzy information condition. The distribution quota of its participants is as follows:

$$
x_{i}=\sum \frac{(s-1) !(n-s) !}{n !}[v(S)-v(S-\{i\})],
$$

where $i=(1,2, \ldots, n)$ represents participants in economic activity, $n$ is the number of participants, and $N=\{1,2, \ldots, n\}$ is a set of participants; $S$ is all subsets which include $i$ belonging to $N$; $S$ is the number of subset members; the marginal contribution $v(s)-v(s-\{i\})$ could be allocated to participant $i$ when this participant joins the coalition. Shapley value model can be regarded as a completely random procedure for all participants by the average expected payoff.

However, the allocation of league members $i$ is no longer a definite value in this paper. It is an interval number that can be expressed as $\left[x_{i}^{-}, x_{i}^{+}\right]$, where $x_{i}^{-}$and $x_{i}^{+}$are the lower and upper bounds of the allocation of $i$.

$$
\begin{aligned}
& x_{i}^{-}=\sum \frac{(s-1) !(n-s) !}{n !}\left[v^{-}(S)-v^{-}(S-\{i\})\right], \\
& x_{i}^{+}=\sum \frac{(s-1) !(n-s) !}{n !}\left[v^{+}(S)-v^{+}(S-\{i\})\right] .
\end{aligned}
$$

In particular, the subtraction of Shapley interval numbers needs to be explained. The interval number subtraction can be regarded as the inverse operation of adding interval numbers [37].

Assuming that $I(R)$ represents a set of all bounded closed intervals on $R, I, J \in I(R)$ and $I=\left[I^{-}, I^{+}\right], J=\left[J^{-}, J^{+}\right]$, then the subtraction of interval numbers can be defined as $I \Theta J=$ $\left[I^{-}-J^{-}, I^{+}-J^{+}\right]$, if and only if $I^{-}-J^{-} \geq I^{+}-J^{+}$.

4.2. Measuring Method of Factors and Coefficients Affecting Alliance Profit Distribution. Whether the surplus benefit distribution mechanism is reasonable and perfect is the key to the successful operation of the strategic alliance. Since the construction of strategic alliances is a contractual model, the rights, obligations, and responsibilities of each stakeholder need to be clearly defined. Therefore, the allocation of profits should consider the resources input, risk sharing, the time to join the alliance, the satisfaction of the members of the alliance, the level of efforts, and so on. If the profits of logistic enterprises are not increased after the alliance, there is no point in forming the alliance, so this paper assumes that the profits of logistic companies after joining the alliance are not less than before. For the effective implementation of the profit distribution rules, we assume that members cannot join or withdraw from the alliance at any time; that is, the alliance receives or eliminates members on a regular basis.
(1) Resource Input. It mainly includes fixed assets, human resources, innovation resources, and other intangible assets. What needs to be explained is the intangible asset. For all enterprises, intangible assets are the brand value of the enterprise, which is also the enterprise image in the minds of customers.

(2) Risk Sharing and Role Positioning. After the establishment of the alliance, alliance members undertake different roles and division of labor in the league, so the risk each member undertakes is inconsistent with their role positioning. Members who take higher risks and more complex works should get the higher profit distribution.

(3) Effort Level. The level of effort is reflected in the quantity and quality of the work done by alliance members in actual operation of the alliance. It mainly constrains the unilateral negative working behavior of members in the alliance and ensures that overall interests of the alliance are not compromised. The indicators can be obtained through assessing the work of alliance members.

(4) Satisfaction of Alliance Members. Most existing researches ignore the importance of alliance members' satisfaction to the overall profit allocation. It has been proved that higher satisfaction could stimulate the enthusiasm of alliance members and the stability of alliance structure. The satisfaction coefficient could be obtained through questionnaire surveys, interviews, and other methods in the group.

\subsection{Multiple Attribute Decision Making Model of Intuitionistic} Fuzzy Sets Based on TOPSIS. TOPSIS (Technique for Order Preference by Similarity to Idea Solution) is a ranking method to ideal solution, which was first proposed by Hwang and Yoon. It has been widely used in multi-index evaluation in recent years [38-41]. The basic idea is that the chosen satisfactory scheme is as close as possible to the positive ideal solution (or scheme) and away from the negative ideal solution as far as possible.

Step 1 (construct the intuitionistic fuzzy sets decision matrix). Supposing $A=\left(a_{1}, a_{2}, \ldots, a_{n}\right)$ is the $n$ enterprises of the whole society logistics enterprise, $B=\left(b_{1}, b_{2}, \ldots, b_{n}\right)$ is the evaluation index set about enterprise. The intuitionistic fuzzy number $x_{i j}=\left(\left\langle u_{i j} v_{i j}\right\rangle\right)$ represents the evaluation value of the $j$ index of enterprise $a_{i}$ where $i=1,2, \ldots, m, j=1,2, \ldots, n$; $0 \leq u_{i j}+v_{i j} \leq 1 ; u_{i j} \in[0,1], v_{i j} \in[0,1]$, respectively, represent the degree of consistency and inconsistency of the evaluation value of the evaluation index $b_{j}$ of the enterprise $a_{i} . \pi_{i j}=1-u_{i j}-v_{i j}$ is the hesitation degree of the enterprise $a_{i}$ on the evaluation index $b_{j}$, and $0 \leq u_{i j}+v_{i j} \leq 1$.

The intuitionistic fuzzy set multiple attribute decision making problem could be expressed as a matrix:

$$
X=\left(x_{i j}\right)_{m \times n} .
$$

Step 2 (determine weights of evaluation indexes by using trapezoidal fuzzy number). There are many methods to determine the weight of evaluation indexes, such as AHP 
(Analytic Hierarchy Process), factor analysis, information entropy, attributing weight, and ordered chain method [42]. However, the above methods have the disadvantages of strong subjectivity, complex algorithm, and large randomness. Nehi and Maleki (2005) [43] proposed intuitionistic trapezoidal fuzzy numbers and some operators for them, which extended discrete set to continuous set. The advantages of this method include the following: (1) it could reflect the fuzziness and uncertainty of expert judgment; (2) without a large amount of data, the calculation method is simple and the judgment matrix is not needed. Therefore, in this paper, the trapezoidal fuzzy number is used to determine the weight of index set.

In the actual decision making, the weights of each index are difficult to accurately determine, which are in a fuzzy interval. It is therefore supposed in this paper that $\omega_{i}=$ $\left(\left\langle\alpha_{i}, \beta_{i}\right\rangle\right)$ represents the weight corresponding to the index $b_{j}$, in which, $0 \leq \alpha_{i}, \beta_{i} \leq 1$ indicate the degree of importance and unimportance of the evaluation index $b_{j}$, respectively, $0 \leq \alpha_{i}+\beta_{i} \leq 1$; all the evaluation indexes could be expressed as intuitionistic fuzzy set vectors:

$$
\begin{aligned}
w & =\left(\omega_{1}, \omega_{2}, \ldots, \omega_{m}\right)^{T} \\
& =\left(\left\langle\alpha_{1}, \beta_{1}\right\rangle,\left\langle\alpha_{2}, \beta_{2}\right\rangle, \ldots,\left\langle\alpha_{m}, \beta_{m}\right\rangle\right)^{T} .
\end{aligned}
$$

According to the definition of intuitionistic trapezoidal fuzzy number, an intuitionistic trapezoidal fuzzy number $A$ with parameters $b_{1} \leq a_{1} \leq b_{2} \leq a_{2} \leq a_{3} \leq b_{3} \leq a_{4} \leq b_{4}$ is denoted as $A=\left\langle\left(a_{1}, a_{2}, a_{3}, a_{4}\right),\left(b_{1}, b_{2}, b_{3}, b_{4}\right)\right\rangle$ in the set of real number $R$. In this case, the membership function and nonmembership function can be given as

$$
\begin{gathered}
\alpha(x)= \begin{cases}0, & x<a_{1} \\
\frac{x-a_{1}}{a_{2}-a_{1}}, & a_{1} \leq x \leq a_{2} \\
1, & a_{2} \leq x \leq a_{3} \\
\frac{x-a_{4}}{a_{3}-a_{4}}, & a_{3} \leq x \leq a_{4} \\
0, & a_{4} \leq x,\end{cases} \\
\beta(x)= \begin{cases}1, & x<b_{1} \\
\frac{x-b_{2}}{b_{1}-b_{2}}, & b_{1} \leq x \leq b_{2} \\
0, & b_{2} \leq x \leq b_{3} \\
\frac{x-b_{3}}{b_{4}-b_{3}}, & b_{3} \leq x \leq b_{4} \\
1, & b_{4} \leq x .\end{cases}
\end{gathered}
$$

The weighted intuitionistic fuzzy set decision matrix is formulated as follows:

$$
R=\left(r_{i j}\right)_{m \times n},
$$

in which

$$
\begin{aligned}
r_{i j} & =\omega_{j} x_{i j}=\left\langle\alpha_{j}, \beta_{j}\right\rangle\left\langle u_{i j}, v_{i j}\right\rangle \\
& =\left\langle\alpha_{j} u_{i j}, \beta_{j}+v_{i j}-\beta_{i} v_{i j}\right\rangle=\left\langle\bar{u}_{i j}, \bar{v}_{i j}\right\rangle .
\end{aligned}
$$

Step 3 (determine intuitionistic fuzzy positive and negative ideal solutions). Suppose that positive ideal solutions $A^{+}$and negative ideal solutions $A^{-}$of the intuitionistic fuzzy sets could be, respectively, expressed as

$$
\begin{aligned}
& A^{+}=\left(r_{1}^{+}, r_{2}^{+}, \ldots, r_{m}^{+}\right)^{T}, \\
& A^{-}=\left(r_{1}^{-}, r_{2}^{-}, \ldots, r_{m}^{-}\right)^{T},
\end{aligned}
$$

in which, $r_{j}^{+}=\left\langle u_{j}^{+}, v_{j}^{+}\right\rangle, r_{j}^{-}=\left\langle u_{j}^{-}, v_{j}^{-}\right\rangle$.

$$
\begin{aligned}
& r_{j}^{+}=\left\{\begin{array}{l}
u_{j}^{+}=\max _{1 \leq i \leq m} \bar{u}_{i j} \\
v_{j}^{+}=\min _{1 \leq i \leq m} \bar{v}_{i j},
\end{array}\right. \\
& r_{i}^{+}=\left\{\begin{array}{l}
u_{j}^{-}=\min _{1 \leq i \leq m} \bar{u}_{i j} \\
v_{j}^{-}=\max _{1 \leq i \leq m} \bar{v}_{i j},
\end{array}\right.
\end{aligned}
$$

in which, $r_{j}^{+}=\left\langle u_{j}^{+}, v_{j}^{+}\right\rangle, r_{j}^{-}=\left\langle u_{j}^{-}, v_{j}^{-}\right\rangle$are all intuitionistic fuzzy values, $0 \leq u_{j}^{+}+v_{j}^{+} \leq 1,0 \leq u_{j}^{-}+v_{j}^{-} \leq 1$.

Step 4 (computing distance). The distance between the enterprise $a_{i}$ and the positive and negative ideal solution is defined as $d\left(a_{i}, A^{+}\right), d\left(a_{i}, A^{-}\right)$, expressed as follows:

$$
\begin{array}{r}
d\left(a_{i}, A^{+}\right) \\
=\sqrt{\frac{1}{2} \sum_{j=1}^{n}\left[\left(\bar{u}_{i j}-u_{j}^{+}\right)^{2}+\left(\bar{v}_{i j}-v_{j}^{+}\right)^{2}+\left(\bar{\pi}_{i j}-\pi_{j}^{+}\right)^{2}\right],} \\
i=1,2, \ldots, m, \\
d\left(a_{i}, A^{-}\right) \\
=\sqrt{\frac{1}{2} \sum_{j=1}^{n}\left[\left(\bar{u}_{i j}-u_{j}^{-}\right)^{2}+\left(\bar{v}_{i j}-u_{j}^{-}\right)^{2}+\left(\bar{\pi}_{i j}-\pi_{j}^{-}\right)^{2}\right],} \\
i=1,2, \ldots, m,
\end{array}
$$

in which, $\overline{\pi_{i j}}=1-\overline{u_{i j}}-\overline{v_{i j}} ; \pi_{j}^{+}=1-u_{j}^{+}-v_{j}^{+} ; \pi_{j}^{-}=1-u_{j}^{-}-v_{j}^{-}$.

Step 5 (calculation of relative closeness and contribution). The calculation of relative closeness between the enterprise $a_{i}$ and the positive ideal solution of $A^{+}$is shown as follows:

$$
\lambda_{i}=\frac{d\left(x_{i}, A^{-}\right)}{d\left(x_{i}, A^{-}\right)+d\left(x_{i}, A^{+}\right)} .
$$

Obviously, $0 \leq \lambda_{i} \leq 1$, and the larger the $\theta_{i}$ is, the higher the overall evaluation of the attributes of the corresponding enterprise $a_{i}$ is. To normalize the $\lambda_{i}$, the contribution rate of enterprise $a_{i}$ in the alliance operation is $\theta_{i}$ :

$$
\theta_{i}=\frac{\lambda_{i}}{\sum_{i=1}^{m} \lambda_{i}},
$$

in which $\sum_{i=1}^{m} \theta_{i}=1$, and the greater the $\theta_{i}$ is, the more profits the enterprises $a_{i}$ should be allocated. 
Step 6 (determination of correction coefficients). The interval Shapley value method holds that the logistics enterprises should bear the resource input, risk sharing, and effort at equal level (i.e., $1 / n$ ) when setting up strategic alliances. However, this is not the actual case, so the benefit allocation correction factor is amended as

$$
\begin{aligned}
\Delta \theta_{i} & =\theta_{i}-\frac{1}{n}, \quad i=1,2, \ldots, m, \\
\sum_{i=1}^{m} \Delta \theta_{i} & =0 .
\end{aligned}
$$

4.4. Improvements considering Stakeholder Satisfaction. In the above section, the profit distribution coefficient of the strategic alliance members has been adjusted according to the actual resource input, the risk taking, and the effort level of the member enterprises. To study the impact of alliance members' satisfaction on overall profit distribution to the structural stability of the strategic alliance, considering the asymmetry of stakeholder satisfaction, the Nash negotiation model is used to adjust the profit distribution scheme. First, determine the stakeholder's satisfaction coefficient to the initial benefit allocation scheme. If stakeholder $i$ is not satisfied with the initial benefit allocation factor, stakeholder $i$ would propose the benefit allocation scheme as

$$
h_{i}=\left(h_{1 i}, h_{2 i}, \ldots, h_{n i}\right)^{T} \quad i=1,2, \ldots, m,
$$

where $h_{j i}$ represents the benefit allocation factor of the strategic alliance member $j$ proposed by the stakeholder $i$, $0 \leq h_{j i} \leq 1$, and $\sum_{j=1}^{n} h_{j i}=1, i=1,2, \ldots, m$. The following discussion shows how to revise the profit distribution scheme proposed by the members of the strategic alliance and how the members of the strategic alliance negotiate and obtain a profit distribution coefficient $\varphi^{*}=\left(\varphi_{1}^{*}, \varphi_{2}^{*}, \ldots, \varphi_{m}^{*}\right)$ and $\sum_{i=1}^{m} \varphi_{i}^{*}=1$ that is satisfactory to all members.

Suppose that the ideal profit distribution scheme of the strategic alliance members is

$$
h^{+}=\left\{h_{1}^{+}, h_{2}^{+}, \ldots, h_{n}^{+}\right\}, \quad \sum_{i=1}^{m} h_{i}^{+} \geq 1 .
$$

Obviously, ideal profit distribution scheme cannot meet the constraint conditions that all the interests of members of the distribution coefficient equal 1 , so, there will be a discount factor $q_{i}$, and the enterprise income distribution coefficient is

$$
\varphi_{i}^{*}=h_{i}^{+}-q_{i}
$$

For the strategic alliance members, the negative ideal scheme is

$$
h^{-}=\left\{h_{1}^{-}, h_{2}^{-}, \ldots, h_{n}^{-}\right\} .
$$

The actual allocation coefficient of the alliance member $i$ should not be less than $h_{i}^{-}$. Otherwise, the members of the alliance would have no initiative to join the alliance, and the satisfaction rate is $\bar{\sigma}_{i}=h_{i}^{-} / h_{i}^{+}$. Obviously, the greater the profit distribution factor $\varphi_{i}^{*}$ of each alliance member is, the higher the member's satisfaction degree $\left(\sigma_{i}=\varphi_{i}^{*} / h_{i}^{+}\right)$of profit distribution plan would be.

Nash has proposed a negotiation model in view of the multiple individual negotiation problem. In this paper, the asymmetric Nash negotiation model is used to solve the final benefit allocation of dynamic logistics alliance, that is, for the ideal scheme $h^{+}=\left\{h_{1}^{+}, h_{2}^{+}, \ldots, h_{n}^{+}\right\}$, seeking the best discount factor $q=\left(q_{1}, q_{2}, \ldots, q_{m}\right)$. The negative value scheme of the strategic alliance enterprise is taken as the starting point of negotiation; that is, $h^{-}=\left(h_{1}^{-}, h_{2}^{-}, \ldots, h_{n}^{-}\right)$. The asymmetric Nash negotiation model is

$$
\begin{array}{ll}
\max & Z=\prod_{i=1}^{m}\left(\frac{\varphi_{1}^{*}}{h_{i}^{+}}-\frac{h_{1}^{-}}{h_{i}^{+}}\right)^{\rho_{i}}, \\
\text { s.t. } & \sum_{i=1}^{m}\left(h_{i}^{+}-q_{i}\right)=1, \\
& h_{i}^{-} \leq h_{i}^{+}-q_{i} .
\end{array}
$$

Formula (41) is the objective function of the Nash negotiation model, where $\rho_{i}$ is the importance of the alliance member $i$ in the entire alliance, which is determined by the profit of the logistics enterprise. The $\left(\varphi_{i}^{*}-h_{i}^{-}\right) / h_{i}^{+}$in the objective function represents the gap between the final profit allocation factor of the member enterprise $i$ and the coefficient of negative ideal allocation scheme. The greater the gap between the two is, the higher the satisfaction degree of strategic alliance enterprises $i$ would be. Therefore, the meaning of the objective function is that all the strategic alliance enterprises could achieve a relatively satisfactory result through negotiation.

Formula (42) is the constraint condition of Nash negotiation model, in which $\sum_{i-1}^{m}\left(h_{i}^{+}-q_{i}\right)=1$ represents the fact that the sum of the final profit sharing coefficients of all strategic alliance members is $1 ; h_{i}^{-} \leq h_{i}^{+}-q_{i}$ indicates that the ultimate profit distribution factor of alliance enterprise $i$ is not less than $h_{i}^{-}$. Otherwise, it would mean that the negotiations fail and the alliance member $i$ would withdraw from the negotiation.

The solution can be obtained by the Kuhn-Tucker condition:

$$
q_{i}^{*}=h_{i}^{+}-h_{i}^{-}-\rho_{i}\left(1-\sum_{i=1}^{m} h_{i}^{-}\right) \frac{\rho_{i} h_{i}^{+}}{\sum_{i=1}^{m} \rho_{i} h_{i}^{+}} .
$$

The profit distribution coefficient of member $i$ is

$$
\phi^{*}=h_{i}^{-}+\rho_{i}\left(1-\sum_{i=1}^{m} h_{i}^{-}\right) \frac{\rho_{i} h_{i}^{+}}{\sum_{i=1}^{m} \rho_{i} h_{i}^{+}} .
$$

In above, it is obtained that the final profit distribution coefficient of the alliance members is $\phi_{i}^{*}$. According to $\phi_{i}^{*}$, we can get the satisfaction degree of the strategic alliance 
TABLE 2: Basic situation and profit of major express enterprises in China.

\begin{tabular}{|c|c|c|c|c|c|c|}
\hline \multirow{2}{*}{ Company } & \multicolumn{4}{|c|}{ Cainiao } & \multirow{2}{*}{ SF } & \multirow{2}{*}{ EMS } \\
\hline & ZTO & YTO & STO & Yunda & & \\
\hline Number of terminal nodes & 23000 & 24000 & 10000 & 24000 & 12068 & 45000 \\
\hline Number of franchisees & 7700 & 2610 & 1495 & 2800 & - & - \\
\hline Number of transport centers & 74 & 82 & 82 & 57 & 294 & - \\
\hline Number of direct transport centers & 68 & 60 & 48 & 54 & 294 & - \\
\hline Direct ratio & $91.9 \%$ & $73.2 \%$ & $58.5 \%$ & $94.7 \%$ & $100 \%$ & $100 \%$ \\
\hline Net profit (2016) & 21.65 & 14 & 12.4 & 12 & 41.8 & 10.3 \\
\hline
\end{tabular}

Note. Data before December 31, 2016.

enterprise $\sigma_{i}$ and then normalize the satisfaction of each alliance member:

$$
\begin{aligned}
\psi_{i} & =\frac{\sigma_{i}}{\sum_{i=1}^{m} \sigma_{i}}, \\
\sum_{i=1}^{m} \psi_{i} & =1 ; \\
\Delta \psi_{i} & =\psi_{i}-\frac{1}{n}, \quad i=1,2, \ldots, n, \\
\sum_{i=1}^{n} \Delta \psi_{i} & =0 .
\end{aligned}
$$

If $\Delta \psi_{i} \geq 0$, this proves that the member's satisfaction degree of the profit distribution scheme is higher than the average level of the alliance members, and then the profit level of the member about satisfaction level should be reduced. If $\Delta \psi_{i} \leq 0$, this proves that the member's satisfaction degree of the profit distribution scheme is lower than the average level of the alliance members, and the profit level of the member about satisfaction level should be increased. Considering the contribution and satisfaction of strategic alliance members, we could get the profit allocation that should be assigned to the private parties.

\section{Case Study}

5.1. The Basic Situation of the Major Express Enterprises in China. In recent years, the express industry has developed rapidly in China, as the basic situation including express volume, express revenue, and growth rate is shown in Figure 4.

Large express enterprises in China mainly include YTO, STO, ZTO, Yunda, SF, and EMS. The YTO, STO, ZTO, Yunda, and Cainiao part of Alibaba established a cooperative relationship, which means YTO, STO, ZTO, and Yunda could deliver goods, pick up goods, and handle other business through offline Cainiao post. In order to facilitate the calculation, this paper would merge "Three Tong One Da" as a Cainiao company and then select Cainiao, SF, and EMS as the research object for case analysis. The basic situation and profits of the major express enterprises in China are shown in Table 2.
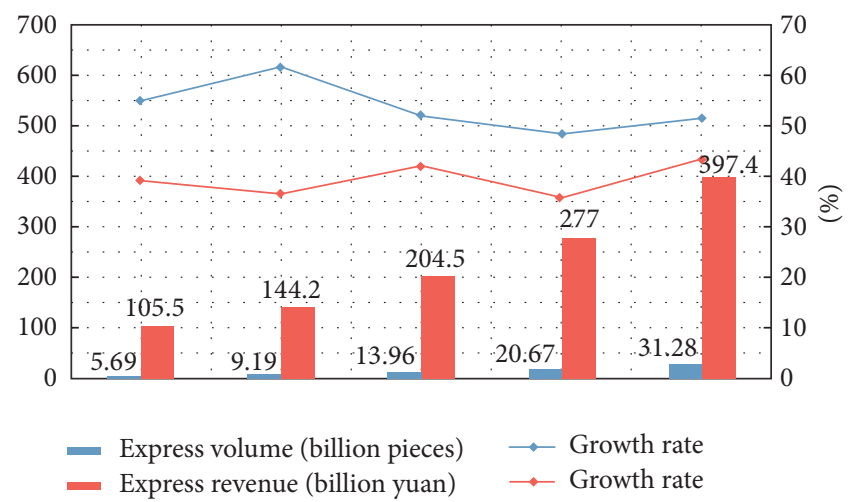

Figure 4: Development of express industry in China.

5.2. Initial Profit Allocation. According to industry estimates, the net profit of main express companies in China would grow further in 2017. To facilitate the calculation, this paper assumes that the net profit of China's major express enterprise would increase by $20 \%-30 \%$, by which the profit range of the main express company in 2017 could be obtained. At the same time, if the express company establishes strategic alliances, the alliance could reduce the logistics process logistics costs and time costs through the integration of information, warehousing, transportation, distribution, and other resources. For example, the truck loading rate in China's logistics industry is only about $50 \%-60 \%$, far less than the United States and other developed countries. However, the vehicle loading rate could be greatly improved to reduce logistics costs and increase the profit through the establishment of strategic alliance. It is assumed that the alliance between two arbitrary express companies could achieve an effect of a $20 \%$ rise in profits through the integration of resources. The basic data are obtained by integrated utilization of qualitative and quantitative methods and shown in Table 3. The total revenue of the strategic alliance cooperation constructed by Cainiao, SF, and EMS is 190.83 206.74 billion yuan.

For the convenience of calculation, we set Cainiao, SF, and EMS as 1, 2, and 3, and distribute profit though original Shapley value method. The data are allocated in Table 3. The profit quota for Cainiao is $x_{1}=[93.86,101.14]$; refer to Table 4 for specific calculations; it is easy to get SF and 
TABLE 3: Express enterprise and strategic alliance profit.

\begin{tabular}{lccc}
\hline Express enterprise & & Profit statement of express enterprise (unit: 100 million yuan) & EMS \\
& Cainiao & SF & {$[103.3,109.75]$} \\
Cainiao & {$[72.06,78.07]$} & {$[146.66,158.89]$} & {$[75.02,81.84]$} \\
SF & {$[146.66,158.89]$} & {$[50.16,54.34]$} & {$[12.36,13.39]$} \\
EMS & {$[103.3,109.75]$} & {$[75.02,81.84]$} & \\
\hline
\end{tabular}

TABLE 4: Calculation table of profit allocation of Cainiao (unit: 100 million yuan).

\begin{tabular}{|c|c|c|c|c|}
\hline$S$ & $\{1\}$ & $\{1,2\}$ & $\{1,3\}$ & $\{1,2,3\}$ \\
\hline$v(s)$ & {$[72.06,78.07]$} & {$[146.66,158.89]$} & {$[103.3,109.75]$} & {$[190.83,206.74]$} \\
\hline$v(s \backslash\{1\})$ & {$[0,0]$} & {$[50.16,54.34]$} & {$[12.36,13.39]$} & {$[75.02,81.84]$} \\
\hline$v(s)-v(s \backslash\{1\})$ & {$[72.06,78.07]$} & {$[96.5,104.55]$} & {$[90.94,96.36]$} & {$[115.81,124.9]$} \\
\hline$|s|$ & 1 & 2 & 2 & 3 \\
\hline$\sigma(|s|)$ & $1 / 3$ & $1 / 6$ & $1 / 6$ & $1 / 3$ \\
\hline$\sigma(|s|)\{v(s)-v(s \backslash\{1\})\}$ & {$[24.02,26.02]$} & {$[16.08,17.43]$} & {$[15.16,16.06]$} & {$[38.60,41.63]$} \\
\hline
\end{tabular}

TABLE 5: Decision matrices and weights.

\begin{tabular}{lcccccc}
\hline & & Initial decision matrix $X$ & & & \multicolumn{2}{c}{ Weighted canonical matrix $R$} \\
& Resource input & Risk sharing \& role positioning & Effort level & Resource input & Risk sharing \& role positioning & Effort level \\
\hline Cainiao & $\langle 0.85,0.1\rangle$ & $\langle 0.75,0.15\rangle$ & $\langle 0.75,0.1\rangle$ & $\langle 0.34,0.505\rangle$ & $\langle 0.22,0.533\rangle$ & $\langle 0.263,0.505\rangle$ \\
SF & $\langle 0.65,0.2\rangle$ & $\langle 0.85,0.1\rangle$ & $\langle 0.85,0.1\rangle$ & $\langle 0.26,0.56\rangle$ & $\langle 0.255,0.505\rangle$ & $\langle 0.298,0.505\rangle$ \\
EMS & $\langle 0.7,0.15\rangle$ & $\langle 0.8,0.15\rangle$ & $\langle 0.85,0.1\rangle$ & $\langle 0.28,0.533\rangle$ & $\langle 0.240,0.533\rangle$ & $\langle 0.298,0.505\rangle$ \\
$w$ & $\langle 0.4,0.45\rangle$ & $\langle 0.3,0.45\rangle$ & $\langle 0.35,0.45\rangle$ & $\langle 0.400,0.450\rangle$ & $\langle 0.300,0.45\rangle$ & $\langle 0.350,0.450\rangle$ \\
\hline
\end{tabular}

EMS's profit quota, which are $x_{2}=[68.78,75.33]$ and $x_{3}=$ $[28.19,30.27]$, respectively. The test shows that the above profit distribution scheme meets the basic conditions for cooperation.

\subsection{Profit Allocation Coefficient Correction}

\subsubsection{Profit Allocation Coefficient Correction Based on Contribution}

(1) Decision Matrix and Weight of Evaluation Index. The experts put three evaluation indexes according to the resources input, risk bearing, role commitment, and the level of effort to assess the three express enterprises. The evaluation information is then processed by statistics and expressed as intuitionistic fuzzy numbers, and the initial decision matrix is obtained. The initial decision matrix $X$ is transformed into a weighted canonical matrix $R$ according to formula (26). Meanwhile, without the consideration of the influence factors of corporation satisfaction, this section directly uses the trapezoidal fuzzy number method to calculate the input of resources, risk weights, roles, and effort level and obtains the membership and nonmembership of evaluation index by statistical method, as shown in Table 5.

(2) Calculation of Ideal Solutions and Their Related Correction Coefficients. Through the weighted norm matrix $R$ and formula (30)-(32), the positive ideal solution $A^{+}$and the negative ideal solution $A^{-}$of intuitionistic fuzzy sets could be obtained, as shown in Table 6 .
TABLE 6: Positive and negative ideal solutions of intuitionistic fuzzy sets.

\begin{tabular}{lccc}
\hline Ideal solution & $b_{1}$ & $b_{2}$ & $b_{3}$ \\
\hline$A^{+}$ & $\langle 0.34,0.505\rangle$ & $\langle 0.255,0.505\rangle$ & $\langle 0.298,0.505\rangle$ \\
$A^{-}$ & $\langle 0.26,0.56\rangle$ & $\langle 0.22,0.533\rangle$ & $\langle 0.263,0.505\rangle$ \\
\hline
\end{tabular}

TABLE 7: Profit allocation correction coefficient of strategic alliance enterprises.

\begin{tabular}{lccccc}
\hline Enterprise & $d\left(a_{i}, A^{+}\right)$ & $d\left(a_{i}, A^{-}\right)$ & $\lambda_{i}$ & $\theta_{i}$ & $\Delta \theta_{i}$ \\
\hline Cainiao & 0.0473 & 0.0708 & 0.599 & 0.409 & 0.075 \\
SF & 0.0708 & 0.0475 & 0.404 & 0.276 & -0.057 \\
EMS & 0.0538 & 0.0468 & 0.465 & 0.315 & -0.018 \\
\hline
\end{tabular}

Formulas (33) are used to calculate the distance $d\left(a_{i}, A^{+}\right)$, $d\left(a_{i}, A^{-}\right)$from enterprise $a_{j}$ to positive and negative ideal solution, respectively. Then we calculate the relative closeness degree $\lambda_{i}$ from enterprise $a_{j}$ to intuitionistic fuzzy positive ideal solution $A^{+}$according to formula (34) (35), normalize the relative closeness degree $\lambda_{i}$ to obtain the $\theta_{i}$, and finally get the correction factor $\Delta \theta_{i}$ by formula (35), as shown in Table 7.

5.3.2. Profit Allocation Coefficient Correction Based on Stakeholder Satisfaction. At the end of the logistics project, in order to get a fairer and more reasonable allocation of profits, it is important to consider the impact of stakeholder satisfaction on the profits allocation after considering resource input, risk taking, role positioning, and effort level. 
TABLE 8: Correction factor of enterprise profit distribution.

\begin{tabular}{lcccccccc}
\hline Enterprise & $\rho$ & $h^{+}$ & $h^{-}$ & $q^{*}$ & $\varphi^{*}$ & $\sigma_{i}$ & $\psi_{i}$ & $\Delta \psi_{i}$ \\
\hline Cainiao & $6 / 11$ & $6 / 11$ & $1 / 3$ & 0.1325 & 0.413 & 0.7572 & 0.413 & 0.08 \\
SF & $4 / 11$ & $5 / 11$ & $1 / 3$ & 0.0916 & 0.3629 & 0.7984 & 0.435 \\
EMS & $1 / 11$ & $1 / 3$ & $1 / 11$ & 0.2403 & 0.0930 & 0.279 & 0.101 \\
\hline
\end{tabular}

TABle 9: Profit distribution comparison.

\begin{tabular}{lcccc}
\hline Enterprise & Interval Shapley & $\begin{array}{c}\text { Only considering } \\
\text { contribution }\end{array}$ & $\begin{array}{c}\text { Only considering stakeholder } \\
\text { satisfaction }\end{array}$ & Comprehensive consideration \\
\hline Cainiao & {$[93.86,101.14]$} & {$[99.55,107.28]$} & {$[90.79,97.89]$} & {$[96.39,103.89]$} \\
SF & {$[68.78,75.33]$} & {$[64.84,70.16]$} & {$[64.99,97.89]$} & {$[60.51,66.34]$} \\
EMS & {$[28.19,30.27]$} & {$[26.44,29.3]$} & {$[35.05,37.61]$} & {$[33.93,36.51]$} \\
\hline
\end{tabular}

According to the Cainiao, SF, and EMS express enterprises' annual profits before alliances, we reasonably assume that the profit allocation coefficients proposed by the novice, SF, and EMS express companies are

$$
h=\left[\begin{array}{lll}
h_{11} & h_{21} & h_{31} \\
h_{12} & h_{22} & h_{32} \\
h_{13} & h_{23} & h_{33}
\end{array}\right]^{T}=\left[\begin{array}{ccc}
\frac{6}{11} & \frac{4}{11} & \frac{1}{11} \\
\frac{5}{11} & \frac{5}{11} & \frac{1}{11} \\
\frac{1}{3} & \frac{1}{3} & \frac{1}{3}
\end{array}\right]^{T} .
$$

According to formula (38)-(46), by asymmetric Nash coordination, the profit allocation model is computed. We obtain importance vector of strategic alliance members $\rho$, government's ideal profit allocation scheme $h^{+}$, negative ideal profit allocation scheme $h^{-}$, profit discount factor $q_{i}^{*}$, partition coefficient $\varphi_{i}^{*}$, and satisfaction degree $\sigma_{i}$, as shown in Table 8.

5.4. Result Analysis. In Section 5.3 we have obtained the profit allocation based on interval Shapley value, the profit allocation correction factor considering contribution, and the stakeholder satisfaction. Therefore, the strategic alliance enterprises' profit allocation could be calculated and shown in Table 9. It is worth mentioning that the profit allocation result is not the final result, and the alliance also needs to pay personal wages. The total wages needed to be paid should be determined according to the actual amount and average price in the actual world.

The results of the profit allocation meet the successful conditions of cooperation. The following could be found according to the comparison:

(1) Compared to the initial allocation scheme of interval Shapley value, only considering the contribution of strategic alliance, the profits of the Cainiao would increase, while the profits of SF and EMS would be reduced to some extent. It is fully reflected by the contribution of the Cainiao enterprises in the formation of strategic alliances, especially in resource input, which is far more than the SF and EMS company.

(2) Compared to the initial allocation scheme of interval Shapley value, only considering the stakeholder satisfaction of strategic alliance, EMS company profits would grow by nearly 25\%, while Cainiao and SF's profits would be reduced to a certain extent. Huge gap of operating profits would lead to the difference between the initial profit allocation coefficients of the three proposed enterprises. As a consequence, the satisfaction degree of profit allocation coefficient of EMS is lower than the average value, which needs compensation.

(3) The comprehensive profit allocation scheme considers the impact of enterprise contribution and the satisfaction of the initial distribution plan of alliance members, which ensures the profit distribution of the fair and protects the enthusiasm of the alliance members and the stability of alliance. Overall, compared to the initial allocation scheme of interval Shapley value, in the scheme of comprehensive profit distribution, the profits of Cainiao and EMS increase a little, while those of SF decreased slightly, which is the result of considering the contribution and satisfaction of the members in the alliance.

\section{Conclusions}

This paper makes full use of social idle logistics capability to provide service to the first mile and the last mile of logistics based on the assumption that all the society logistics providers build logistics strategic alliances, analyze customer's logistics preference through the customer shopping behavior data recorded by the electricity supplier, and then classify them as higher speed, lower cost, and lower carbon emissions, respectively. The paper constructs different objective function models according to different preferences and puts forward a kind of intensive distribution logistics network design considering sharing economy, which is solved by metaheuristics to get the approximate solution, to provide a new direction for the study of cyclic network design.

The rationality of profit distribution is the key to the sustainable operation of the alliance. Considering the benefits fuzziness of the actual cooperative game, an improved interval Shapley value method which considers both the member satisfaction and the contribution is proposed to make up for the deficiency of the similar research. Taking the major express enterprises in China as a case study, the results show that, compared with the traditional interval Shapley value 
method, the profit distribution coefficient calculated from the improved interval Shapley value model could not only make profit distribution more equitable, but also improve stakeholder satisfaction to promote the sustainable development of alliance.

\section{Conflicts of Interest}

The authors declare that they have no conflicts of interest.

\section{Acknowledgments}

This work is supported by the Natural Science Foundation of China (NSFC no. 71403225 and no. 71728001), the Energy Foundation (no. G-1709-26901), the Soft Science Foundation of Sichuan Province and Chengdu City (no. 2014ZR0019/no. 2015-RK00-00220-ZF), and the Cyclic Economic Center of Sichuan Province (Project no. XHJJ-1411).

\section{References}

[1] A. Taeihagh, "Crowdsourcing, sharing economies and development," Journal of Developing Societies, vol. 33, no. 2, pp. 191-222, 2017.

[2] DOUGH, "Driving for ubereats: what it's like delivering food for uber," via https://www.ridesharingdriver.com/, 29 March 2016.

[3] F. Manjoo, "Grocery deliveries in sharing economy," via https://www.nytimes.com, 21 May 2014.

[4] S. A. O'Brien, "The Uber effect: instacart shifts away from contract workers, 22-06-2015," CNNMoney, Retrieved 02-042017.

[5] China Federation of logistics \& purchasing, "Total social logistics," via http://www.chinawuliu.com.cn/, 8 March 2013.

[6] M.-S. Viktor, C. Kenneth, Y. Sheng, and T. Zhou, Big Data Age: Great Changes in Life, Work and Thinking, Zhejiang people's press, 2013.

[7] J. Fisk and P. McKeown, "The pure fixed charge transportation problem," Naval Research Logistics Quarterly, vol. 26, no. 4, pp. 631-641, 1979.

[8] R. S. Barr, F. Glover, and D. Klingman, "A new optimization method for large scale fixed charge transportation problems," Operations Research. The Journal of the Operations Research Society of America, vol. 29, no. 3, pp. 448-463, 1981.

[9] Z.-J. M. Shen, C. R. Coullard, and M. S. Daskin, "A joint location-inventory model," Transportation Science, vol. 37, no. 1, pp. 40-55, 2003.

[10] B. Jansen, P. C. Swinkels, G. . Teeuwen, B. van Antwerpen de Fluiter, and H. Fleuren, "Operational planning of a largescale multi-modal transportation system," European Journal of Operational Research, vol. 156, no. 1, pp. 41-53, 2004.

[11] B. M. Beamon, "Supply chain design and analysis: models and methods," International Journal of Production Economics, vol. 55, no. 3, pp. 281-294, 1998.

[12] N. Gülpınar, D. Pachamanova, and E. Çanakoğlu, "Robust strategies for facility location under uncertainty," European Journal of Operational Research, vol. 225, no. 1, pp. 21-35, 2013.

[13] M. H. F. Zarandi, A. Hemmati, S. Davari, and I. B. Turksen, "Capacitated location-routing problem with time windows under uncertainty," Knowledge-Based Systems, vol. 37, pp. 480489, 2013.
[14] D. Konur and J. Geunes, "Competitive multi-facility location games with non-identical firms and convex traffic congestion costs," Transportation Research Part E: Logistics and Transportation Review, vol. 48, no. 1, pp. 373-385, 2012.

[15] L. Özdamar, E. Ekinci, and B. Küçükyazici, "Emergency logistics planning in natural disasters," Annals of Operations Research, vol. 129, pp. 217-245, 2004.

[16] Z. Guo, D. Zhang, H. Liu, Z. He, and L. Shi, "Green transportation scheduling with pickup time and transport mode selections using a novel multi-objective memetic optimization approach," Transportation Research Part D: Transport and Environment, 2015.

[17] M. Gan, X. Liu, S. Chen, Y. Yan, and D. Li, "The identification of truck-related greenhouse gas emissions and critical impact factors in an urban logistics network," Journal of Cleaner Production, vol. 178, pp. 561-571, 2018.

[18] L. S. Shapley, "A value for $n$-person games", in Contributions to the Theory of Games, vol. 2 of Annals of Mathematics Studies, No. 28, pp. 307-317, Princeton University Press, Princeton, NJ, USA, 1953.

[19] L. S. Shapley, "Cores of convex games," International Journal of Game Theory, vol. 1, pp. 11-26, 1971.

[20] R. J. Weber, "Probabilistic values for games," in The Shapley value, pp. 101-119, Cambridge University Press, Cambridge, 1988.

[21] D. Schmeidler, "The nucleolus of a characteristic function game," SIAM Journal on Applied Mathematics, vol. 17, pp. 11631170, 1969.

[22] I. Giannoccaro and P. Pontrandolfo, "Supply chain coordination by revenue sharing contracts," International Journal of Production Economics, vol. 89, no. 2, pp. 131-139, 2004.

[23] D. Gupta and W. Weerawat, "Supplier-manufacturer coordination in capacitated two-stage supply chains," European Journal of Operational Research, vol. 175, no. 1, pp. 67-89, 2006.

[24] B. Verspagen and G. Duysters, "The small worlds of strategic technology alliances,” Technovation, vol. 24, no. 7, pp. 563-571, 2004.

[25] L. S. Shapley, Additive and Non-Additive Set Functions, Princeton University, 1953.

[26] G. Owen, "Communications to the Editor-a note on the Shapley value," Management Science, vol. 14, no. 11, pp. 731-731, 1968.

[27] G. Owen, "Multilinear extensions of games," Management Science, vol. 18, pp. 64-79, 1972.

[28] E. Kalai and D. Samet, “On weighted Shapley values," International Journal of Game Theory, vol. 16, no. 3, pp. 205-222, 1987.

[29] M. A. Shi-hua and W. Peng, "The study of profit allocation among partners in supply chain based on the Shapley value," Industrial Engineering and Management, vol. 4, pp. 43-45, 2006.

[30] L. A. Guardiola, A. Meca, and J. Timmer, "Cooperation and profit allocation in distribution chains," Decision Support Systems, vol. 44, no. 1, pp. 17-27, 2007.

[31] Y. Wang, X. Ma, M. Liu et al., "Cooperation and profit allocation in two-echelon logistics joint distribution network optimization," Applied Soft Computing, vol. 56, pp. 143-157, 2017.

[32] L. Petrosjan and G. Zaccour, "Time-consistent Shapley value allocation of pollution cost reduction," Journal of Economic Dynamics \& Control, vol. 27, no. 3, pp. 381-398, 2003.

[33] D. A. I. Jian-hua and X. U. E. Hen-xin, "The strategy of profit allocation among partners in dynamic alliance based on the 
Shapley value," Chinese Journal of Management Science, pp. 4-7, 2004.

[34] J.-P. Aubin, "Cooperative fuzzy games," Mathematics of Operations Research, vol. 6, no. 1, pp. 1-13, 1981.

[35] M. Sakawa and I. Nishizaki, "A solution concept based on fuzzy decisions in $n$-person cooperative games," Japanese Journal of Fuzzy Theory and Systems, vol. 4, no. 2, pp. 183-194, 1992.

[36] M. Mares, Fuzzy Cooperative Games: Cooperation with Vague Expectations, vol. 72 of Studies in Fuzziness and Soft Computing, Physica, New York, NY, USA, 2001.

[37] W. Han, H. Sun, and G. Xu, "A new approach of cooperative interval games: the interval core and Shapley value revisited," Operations Research Letters, vol. 40, no. 6, pp. 462-468, 2012.

[38] D. L. Olson, "Comparison of weights in TOPSIS models," Mathematical and Computer Modelling, vol. 40, no. 7-8, pp. 721727, 2004.

[39] G. Tzeng, C. Lin, and S. Opricovic, "Multi-criteria analysis of alternative-fuel buses for public transportation," Energy Policy, vol. 33, no. 11, pp. 1373-1383, 2005.

[40] T. Yang and P. Chou, "Solving a multiresponse simulationoptimization problem with discrete variables using a multipleattribute decision-making method," Mathematics and Computers in Simulation, vol. 68, no. 1, pp. 9-21, 2005.

[41] S.-H. Tsaura, T.-Y. Chang, and C.-H. Yen, "The evaluation of airline service quality by fuzzy MCDM," Tourism Management, vol. 23, no. 2, pp. 107-115, 2002.

[42] D.-F. Li, "An approach to fuzzy multiattribute decision making under uncertainty," Information Sciences, vol. 169, no. 1-2, pp. 97-112, 2005.

[43] H. M. Nehi and H. R. Maleki, "Intuitionistic fuzzy numbers and its applications in fuzzy optimization problem," in Proceedings of the 9th WSEAS International Conference on Systems, pp. 1-5, Athens, Greece, 2005. 


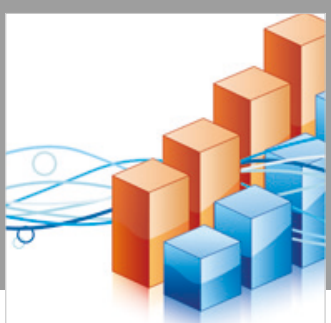

Advances in

Operations Research

\section{-n-m}
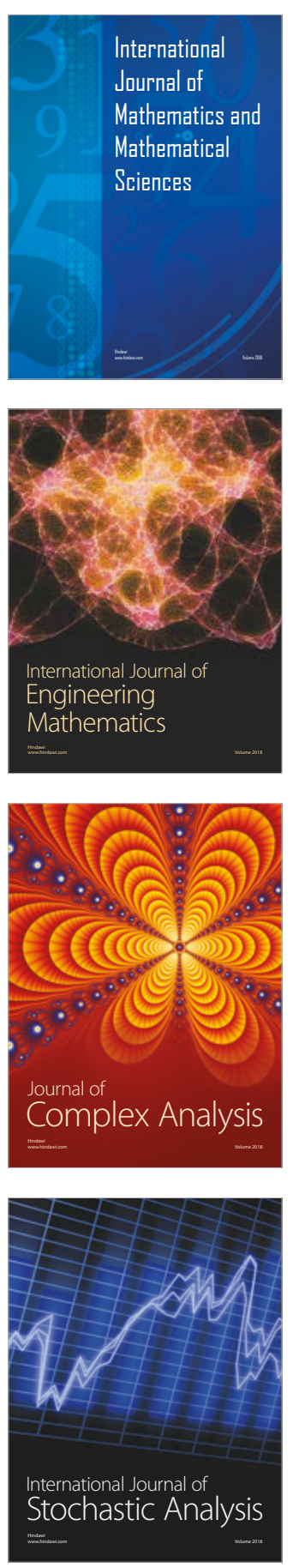
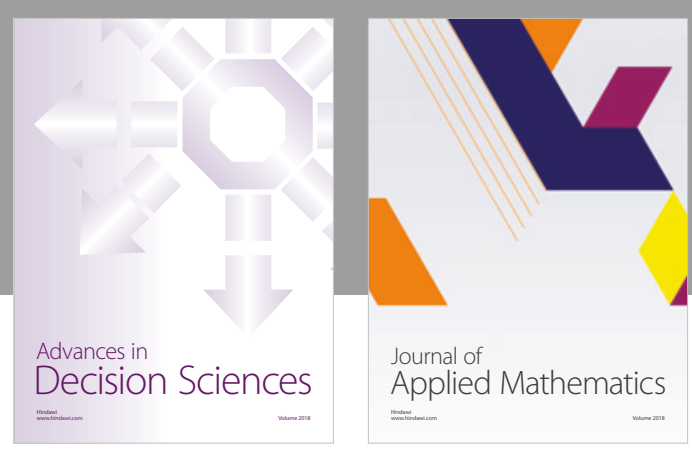

Journal of

Applied Mathematics
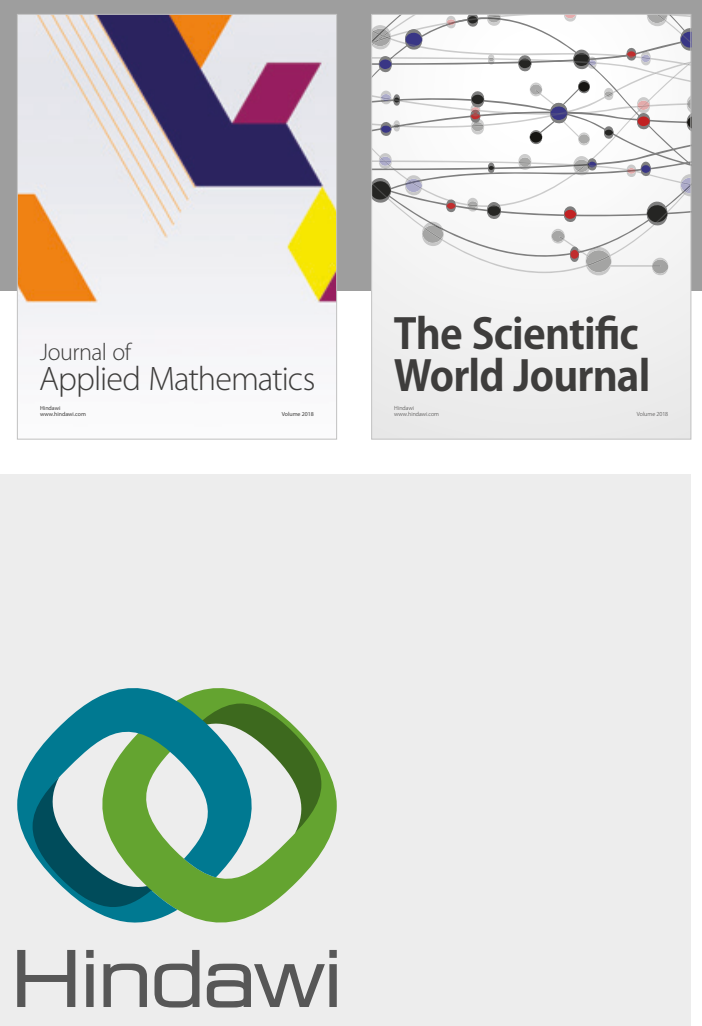

Submit your manuscripts at

www.hindawi.com

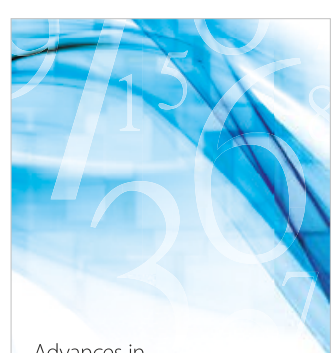

Advances in
Numerical Analysis
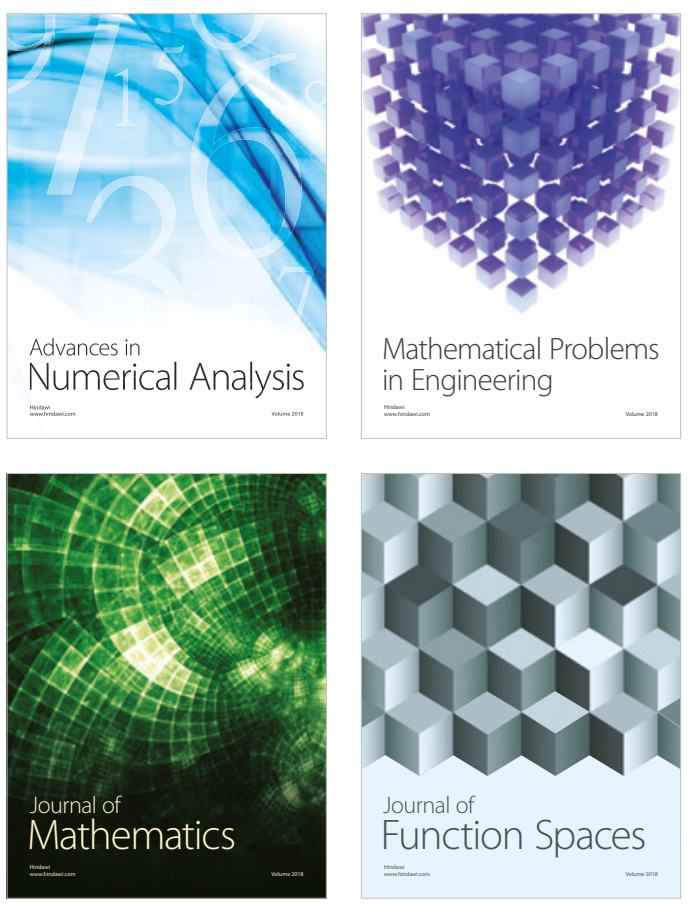

Mathematical Problems in Engineering

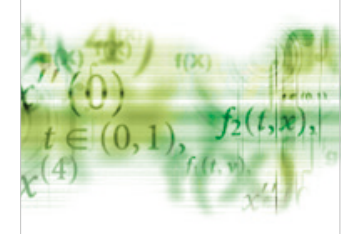

International Journal of

Differential Equations

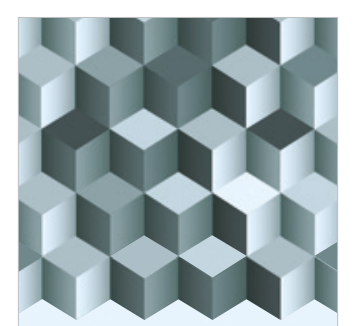

Journal of

Function Spaces
The Scientific

World Journal

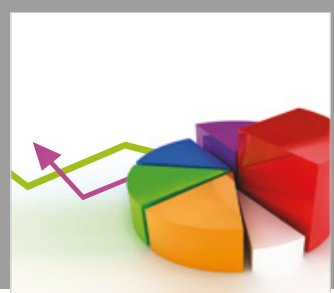

Journal of

Probability and Statistics
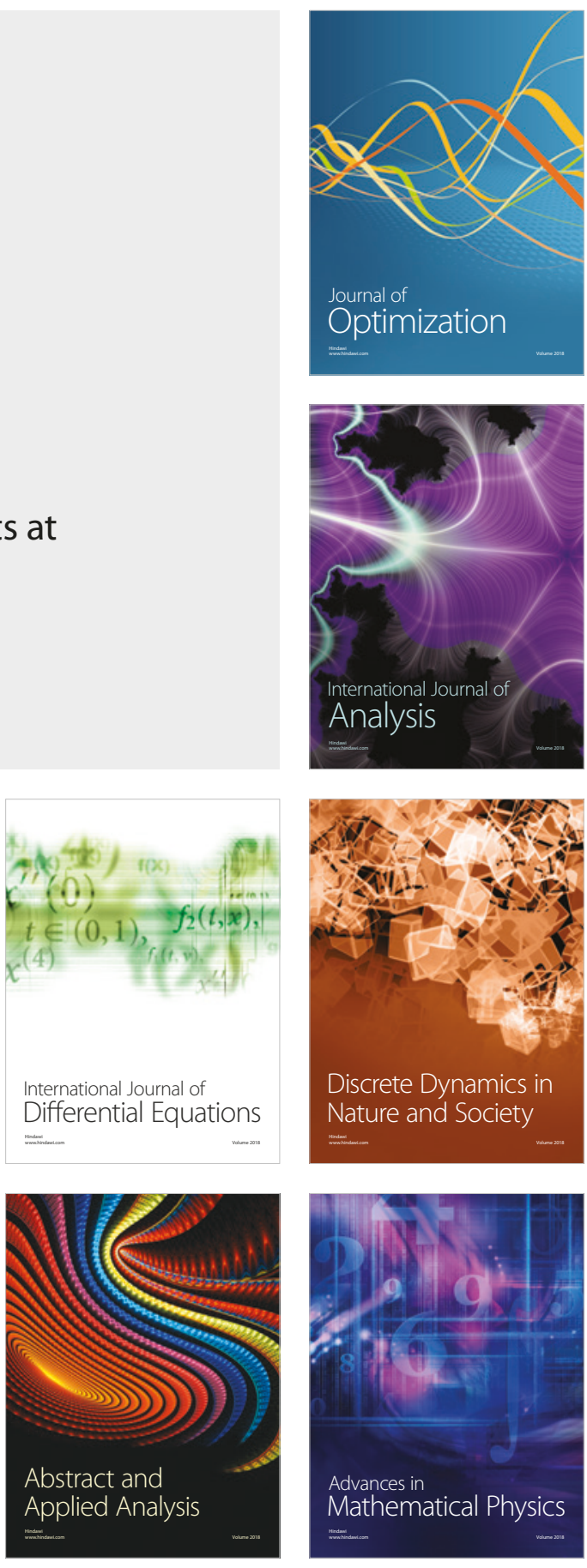